\author{
Military Technical College \\ Kobry El-Kobbah, \\ Cairo, Egypt
}

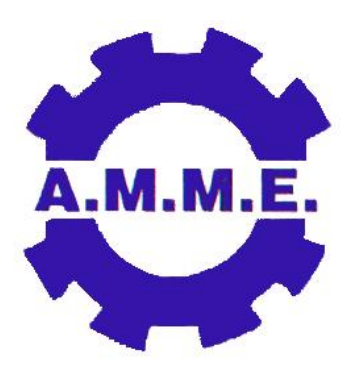

14th International Conference on Applied Mechanics and Mechanical Engineering.

\title{
Synthesis and Characterization of Laminated Si/SiC Composites
}

\author{
By \\ S.M. Naga * \\ S. H. Kenawy* \\ M. Awaad* \\ H. S. Abd El-Wahab* \\ P.Greil** \\ M.S.Abdir ${ }^{\star * *}$.
}

\begin{abstract}
:
Laminated $\mathrm{Si} / \mathrm{SiC}$ ceramics were synthesized from porous preforms of biogenous carbon impregnated with Si slurry at a temperature of $1500^{\circ} \mathrm{C}$ for 2 hours. Due to the capillarity infiltration with $\mathrm{Si}$, both intrinsic micro- and macrostructure in the carbon preform were retained within the final ceramics. The SEM micrographs indicate that the final material exhibits a distinguished laminar structure with successive Si/SiC layers. The produced composites show weight gain of $\approx 5 \%$ after heat treatment in air at $1300{ }^{\circ} \mathrm{C}$ for $50 \mathrm{~h}$. The produced bodies could be used as high temperature gas filters as indicated from the permeability results.
\end{abstract}

\section{Keywords:}

Laminates, Si/SiC composites, microstructure, permeability, oxidation resistance 
** Unversity of Erlangen-Nuernberg, Department of Materials Science (III), Erlangen, Germany

*** Cairo University, Chemical Engineering Dept., Cairo, Egypt

\section{Introduction:}

Porous SiC ceramics have been a focus of attention in the field of porous ceramics due to their superior properties, such as low thermal expansion coefficient, high thermal conductivity and excellent mechanical strength ${ }^{(1-3)}$. However, their brittleness limits their use in most structural applications.

To improve fracture resistance in brittle-matrix composites, the use of a weak interface that promotes crack deflection is necessary ${ }^{(4)}$. The earliest ceramics composites used as interfaces are boron nitride or carbon; however, these materials are prone to oxidation at high temperature. Porous-oxide layers seem to be an attractive alternative and have been successfully demonstrated as effective interface layers in laminated ceramic composites ${ }^{(5,}$ 6). Laminated system consisting of porous- $-\mathrm{Al}_{2} \mathrm{O}_{3}$ interfaces between $\mathrm{Al}_{2} \mathrm{O}_{3}$ bars showed markedly improved fracture resistance for these composites as compared with monolithic $\mathrm{Al}_{2} \mathrm{O}_{3}{ }^{(5)}$.

Clagg et.al ${ }^{(7)}$ have produced laminated SiC with graphite interface layers. These multilayer SiC composites showed apparent toughness and fracture energy 5 and 200 times respectively higher than the typical values of monolithic $-\mathrm{SiC}$. Recently, it was shown that laminated composites without weak interfaces also exhibited damage-tolerant behaviours ${ }^{(8,9)}$.

Due to its internal sintering, $\mathrm{SiC}$ ceramics are usually fabricated at extremely high temperature ${ }^{(10)}$. Thus the key problem is how to prepare porous $\mathrm{SiC}$ ceramics at relatively low temperature ${ }^{(11)}$. Usually, oxide with low sintering temperature may be added into the starting materials to form oxide bonded porous SiC ceramics. These oxide bonded porous ceramics possess weak bonding interface between $\mathrm{SiC}$ and oxides which thus impairs the properties of porous $\mathrm{SiC}$ ceramics ${ }^{(12)}$.

The oxidation of $\mathrm{SiC}$ is well documented in the literature. The oxidation can lead to the formation of $\mathrm{SiO}_{2}$ and $\mathrm{CO} / \mathrm{CO}_{2}$ (passive oxidation), with an increase in weight and passivation of the surface, or to $\mathrm{SiO}$ and $\mathrm{CO}$ (active oxidation). In the latter case there is no passivating layer formed on the surface of the SiC and there is continual loss of material. Active oxidation however, is possible only at low oxygen partial pressure or very high temperature. In case of presence of water vapour the reactions are different, and an oxidation with continual removal of the oxidized layer is possible ${ }^{(13-15)}$.

In the present study, a novel method of synthesizing laminated $\mathrm{Si} / \mathrm{SiC}$ composite is described, by which $\mathrm{SiC}$ multilayer ceramic can be fabricated of biomorphic materials. The Physical and mechanical properties of the samples were investigated together with their oxidation resistance in air, microstructure and phase composition. The kinetics of oxidation is also studied.

\section{Experimental procedure:}

\section{2-1- specimen preparation}

The substrates used in this study are flat woven-cellulosic fabric performs, Fig (1). It is a woven $100 \%$ cotton fabric with a plain structure $1 / 1$ (usually called DUCK fabrics). It is heavy fabrics with high tensile strength $(1.8 \mathrm{MPa})$ usually used in tents, fabric ceilings. The warp \& weft counts (diameter) are thick yarns. It possesses an air permeability of 4.68 at WG $12.7 \mathrm{~mm}\left(\mathrm{~cm}^{3} / \mathrm{cm}^{2} / \mathrm{sec}\right.$.). The fabrics were cut to $10 \times 10 \mathrm{~cm}^{2}$ squares. About 15 
plates were stacked together forming a plate with dimensions of $10 \times 10 \times 1 \mathrm{~cm}^{3}$. To obtain flat samples the cellulosic fabric layers are placed between two light weight ceramic plates applying a load of $10 \mathrm{~N}$, so that they cannot deform during the carbonization process. A slow heating rate of $1^{\circ} \mathrm{C} / \mathrm{min}$ in a $\mathrm{N}_{2}$ atmosphere was applied up to $350^{\circ} \mathrm{C}$ with a soaking time of $2 \mathrm{~h}$ at the peak temperature. On a second ramp the samples were heated at $1^{\circ} \mathrm{C} /$ min up to $800^{\circ} \mathrm{C}$ and kept at that temperature for $1 \mathrm{~h}$, before cooling down to room temperature. The obtained carbon templates were used as preforms for the following infiltration process. Si powder ( Elken HQ with particle size from 1-10 $\mu \mathrm{m}$ ) dispersed in isopropyl alcohol in the presence of a dispersing agent (Hypermer; polyalkylene amine derivative) was used as infiltrant. The pyrolyzed carbon specimens were impregnated with two silicon slurries differing in silicon loading (4.5 wt.\% and $8 \mathrm{wt} \%)$, under a low pressure of $10^{4} \mathrm{~Pa}$ for $1 \mathrm{~h}$ to ensure complete impregnation. After drying at $90^{\circ} \mathrm{C}$, heat treatment at $1500^{\circ} \mathrm{C}$ with a soaking time of $2 \mathrm{~h}$ at the peak temperature in a graphite reactor under vacuum of $\approx 1 \mathrm{~Pa}$ resulted in the formation of a laminated porous Si/SiC composite. The obtained $\mathrm{Si} / \mathrm{SiC}$ plates were cut into bars of $5 \mathrm{X} 1 \mathrm{X} 1 \mathrm{~cm}^{3}$ for further investigation.

\section{2-2 Characterization:}

The bulk density and open porosity of the fabricated composites were evaluated using the Archimedes method (ASTM C-20) with water as liquid medium. XRD analysis of powdered samples using monochromatic $\mathrm{Cu} \mathrm{K}_{\alpha}$ radiation (D 500, Siemens, Mannheim, Germany) was used to identify crystalline reaction products. Microstructures were observed using SEM (Model XL 30, Philips, Eindhoven, Netherlands). Bending strength was measured using a three point bending test on a universal testing machine (Model 4204, Instron Corp., Danvers, Mass.) at a crosshead speed of $1 \mathrm{~mm} / \mathrm{min}$. At least 10 specimens with the dimensions of $50 \times 10 \times 10 \mathrm{~mm}$ were measured.

The samples fracture toughness was determined a single-edge notch specimen using the three-point bending method according to the produced outlined in ASTM E399-90(1992). The notch was made with a diamond raw. Tests were performed cross head speed of 0.5 $\mathrm{mm} / \mathrm{min}$ and load-point displacement were recorded continuously during the tests using a computer controlled materials testing machine (Model LRX-plus; L Lloyd instruments Ltd., Fareham, UK). The permeability of air through specimens was measured at $0.1 \mathrm{MPa}$. of gas pressures difference in a permeation test cell. Permeability was determined according to Darcy's law.

$$
K=\frac{q \cdot L \cdot \eta}{\Delta p \cdot A}
$$

Where: q: mass flow $\left(\mathrm{m}^{3} / \mathrm{s}\right)$, L: sample thickness $(\mathrm{m}), \mathrm{\eta}$ : air dynamic viscosity (Pa.s), $\Delta \mathrm{p}$ : back pressure $(\mathrm{Pa})$ and $A$ : sample area $\left(\mathrm{m}^{2}\right)$.

1 Darcy $(D)=0.9869233 \times 10^{-12} \mathrm{~m}^{2}$, Sl-unit of $\mathrm{K}=1.02325 \times 10^{12} \mathrm{D}$.

Mercury porosimetry (Model pore sizer 9320, Micromerities, USA) was used to measure the samples average pore size and pore area.

The thermal oxidation resistance of the $\mathrm{Si} / \mathrm{SiC}$ composite was examined in air under static conditions at $1300^{\circ} \mathrm{C}$. The samples were kept at the peak temperature for definite time intervals. Then the samples were taken out, cooled in dissector and weighted with accuracy $\pm 0.1 \mathrm{mg}$. The total time of testing was $50 \mathrm{~h}$ 


\section{Results and Discussion :}

\section{3-1 Carbonization}

The pyrolysis of the cellulosic fabrics has a great effect on the properties of the composite. It is important to choose a pyrolysis temperature appropriate for avoiding distortion and crack formation during the carbonization. Figure (2) shows the TG curve of the raw textile. It shows that the weight loss started below $100^{\circ} \mathrm{C}$ and was almost terminated at $500^{\circ} \mathrm{C}$.

The maximum decomposition rate was in the temperature range of $245^{\circ} \mathrm{C}-400^{\circ} \mathrm{C}$. Mechanisms involved in the conversion of cellulose to carbon are ${ }^{(16)}$ : [1] desorption of adsorbed water up to $150^{\circ} \mathrm{C}$, [2] splitting off of cellulose structure water between $150^{\circ} \mathrm{C}$ and $240^{\circ} \mathrm{C}$, [3] chain scissions, or depolymerization, and breaking of $\mathrm{C}-\mathrm{O}$ and $\mathrm{C}-\mathrm{C}$ bonds within ring units evolving water, $\mathrm{CO}$ and $\mathrm{CO}_{2}$ between $240^{\circ} \mathrm{C}$ and $400^{\circ} \mathrm{C}$, [4] aromatization forming carbon layers above $400^{\circ} \mathrm{C}$ and [5] completion of the decompositions and rearrangements, leaving a carbon template structure.

Cellulose breaks down with a stepwise manner at $245-475^{\circ} \mathrm{C}$, and the total weight loss of about $75 \%$ (Fig. 2 ) occurred due to evolution of $\mathrm{H}_{2} \mathrm{O}, \mathrm{CO}_{2}$ and volatile hydrocarbons from fragmentation reactions of the polyaromatic components. The mass loss of the textile preforms after carbonization up to $1000^{\circ} \mathrm{C}$ is about $80 \mathrm{wt} \%$.

\section{3-2 Microstructure}

XRD patterns of the bodies fired at $1500^{\circ} \mathrm{C}$ Fig. $(3 \mathrm{a}, \mathrm{b})$ showed that the only phases present are $\beta-\mathrm{SiC}$ and $\mathrm{Si}$. In both compositions, there is no evidence for residual carbon or crystalline $\mathrm{SiO}_{2}$ phase. The residual content of free silicon amounts to $11.8 \mathrm{vol}$. $\%$ in the specimen infiltrated with the $4.5 \mathrm{wt}$. \% Si slurry and 30.8 Vol.\% for $8 \mathrm{wt}$. \% Si slurry, respectively. The reaction mechanism of liquid $\mathrm{Si}$ with the porous carbon template can be divided into four stages: ${ }^{(17)}$

1- Nucleation stage: heterogeneous nucleation of nano-scaled $\mathrm{SiC}$ grains on the inner surface of the carbon template by reaction with $\mathrm{Si}$ vapor below the melting point of $\mathrm{Si}(\mathrm{T}<$ $\left.1410^{\circ} \mathrm{C}\right)$.

2- Initial stage: Simultaneous nucleation of nano-grained and coarse-grained $\beta$-SiC after Si melt infiltration.

3- Intermediate stage: diffusion-controlled growth of the $\beta-\mathrm{SiC}$ layer into the carbon struts.

4- Final stage: dissolution of the nano-grained $\mathrm{SiC}$ in the $\mathrm{Si}$ melt and re-crystallization on coarse-SiC grains resulting in a coarsening of the coarse-grained $\mathrm{SiC}$ phase $\left(\mathrm{T}>1400^{\circ} \mathrm{C}\right)$.

The density of $\mathrm{Si} / \mathrm{SiC}$ composites containing $4.5 \mathrm{wt} \% \mathrm{Si}$ and fired at $1500{ }^{\circ} \mathrm{C}$ is $0.7 \mathrm{~g} / \mathrm{cm}^{3}$ 
and their apparent porosity is $48.13 \%$. Increasing $\mathrm{Si}$ content to 8 wt\% filled the body preexisting pores with $\mathrm{Si}$, increases the composite bulk density to $2.10 \mathrm{~g} / \mathrm{cm}^{3}$ and decreases the apparent porosity to $17.93 \%$. Table (1) shows the densification parameters of the produced bodies.

A low temperature pyrolysis at $800^{\circ} \mathrm{C}$ of the cellulosic fabrics followed by infiltration of $\mathrm{Si}$ into the skeletal carbonaceous preforms under pressure and firing at $1500^{\circ} \mathrm{C}$ produces $\mathrm{Si} / \mathrm{SiC}$ composites with structure of the native cellulosic fabrics, Fig.(4a). The gaps between carbon layers after carbonization were filled with silicon and exhibited a distinguished laminated microstructure, Fig. (4b). Figure (43c) indicates the development of a mixture of fine grain and needle-like $\mathrm{SiC}$ whiskers between the composite fibers. The needle-like whiskers had been grown in situ. They were grown by the vapour phase reaction between $\mathrm{SiO}$ and $\mathrm{CO}$ during the reaction ${ }^{(18)}$. The in situ grown $\mathrm{SiC}$ whiskers were observed by many authors during the synthesis of biomorphic SiC ceramics from mineralized cellulosic preforms ${ }^{(19-21)}$.

\section{3-5 Permeability Measurement}

The fluid permeability is an important parameter for porous ceramics. Liu et al. indicated in their study that the gas permeability of the ceramics specimens is dependent on the average pore size than the open porosity. Plot of the gas flow rate vs. applied pressure gradient is given in Fig. (5) This plot is linear, showing that flow is in a good agreement with Darcy's law. Multiplying the slope of this line with the viscosity $\eta$ of the fluid yields the permeability K. Accordingly; $\mathrm{K}$ results are illustrated in Table (1).

In porous SiC ceramics, there are mainly two kinds of pores. Small pores derived from the stack of SiC particles, and large pores formed by burning out carbon particles ${ }^{(23)}$. More carbon content in the green bodies increases the number of the large pores, resulting in higher open porosity. The high porosity improves the connectivity of open pores and then reduces the tortuosity of pore channels. Furthermore, plenty of large pores by burning out carbon particles enlarge the average pore diameter in porous $\mathrm{SiC}$ ceramics. The higher open porosity, large average pore diameter and lower tortuosity lead to the large Darcian permeability ${ }^{(24)}$.

Due to the abrupt increase of the open porosity and pore size caused by the lamination of porous $\mathrm{Si} / \mathrm{SiC}$ composite, more pore walls were formed, and the interaction between flowing gas and pore walls is enhanced. The Darcian permeability of the produced laminated $\mathrm{Si} / \mathrm{SiC}$ composites was found to be $2.8 \times 10^{-10} \mathrm{~m}^{2}$, which is in the order of magnitude of gas filter supports, and, therefore, the produced bodies are suitable for several technological applications.

\subsection{Pore Analysis}

The analysis of pore size distribution carried out for the carbon substrate and the Si/SiC composite shows a variation in pore area, pore volume and size in the developed pore system of the composite.

Table (1) shows that the size and distribution of pores greatly effected by the infiltration of carbon by $\mathrm{Si}$, Figure $(6 \mathrm{a}, \mathrm{b})$ shows the pore size distribution of the measured samples.

Carbon substrate (fig.6a) shows pore proportion in the range of 150.99 to $31.26 \mu \mathrm{m}$, with some fine fraction concentrated in the range from 0,060 to $0.012 \mu \mathrm{m}$ range. On the other hand, $\mathrm{Si} / \mathrm{SiC}$ composites takes on a bimodal pore size distribution at 159.47 and 53.97 $\mu \mathrm{m}$, with some in fine fraction 0.030 to $0.006 \mu \mathrm{m}$. Infiltration of $C$ substrates decreases the 
open porosity. It seams that the acute viscous Si flow promotes the closure of small pores and the shrinkage of large pores, leading to the decrease in open porosity and pore size, Table (1).

\section{3-7 Mechanical Properties:}

Table (2) shows the bending strength of $\mathrm{Si} / \mathrm{SiC}$ composites laminates. It is obvious that the bending strength of the composites infiltrated with $8 \mathrm{wt} \% \mathrm{Si}$ is higher than that infiltrated with $4.5 \mathrm{wt} \% \mathrm{Si}$. The low porosity (17.93\%) of the Si/SiC composites infiltrated with 8 wt \% Si played a significant role in increasing its bending strength. This suggested that the silicon content was the critical factor influencing the final bending strength. Accordingly, the mechanical properties of these materials can be considered as a continuous network of $\mathrm{SiC}$ with residual $\mathrm{Si}$.

Si-SiC composites display a nonlinear stress-strain behavior when tensile loaded parallel to the fiber direction. This nonlinearity is related to the occurrence of damaging phenomena, mainly including multiple matrix microcracking and fiber matrix-deponding. They are often referred to as damageable elastic materials ${ }^{(27)}$. Figure $(7)$ shows that the crack deflection occurs at the $\mathrm{Si} / \mathrm{SiC}-\mathrm{Si} / \mathrm{SiC}$ interface. Further loading causes the formation of some new cracks in the next $\mathrm{Si} / \mathrm{SiC}$ layer. This process is repeated until all the $\mathrm{Si} / \mathrm{SiC}$ layers are cracked, resulting in a saw-structure response.

Values reported for the fracture toughness of bioSiC for crack propagation perpendicular to the axial direction are in agreement with the results obtained here ${ }^{(28)}$. The multilayer $\mathrm{Si} / \mathrm{SiC}$ samples studied here sustain stress after the outset of fracture. The determination phenomena allow for signification sample deformation before final breaking. The delamination mechanism, which provides a toughness effect, is responsible for the fracture toughness improvement. Crack cannot easily propagate from one layer to anther, so that each layer fails singularly rather than sudden fracture. The residual silicon plays a role as well. It could divert the crack from the path of the minimum energy resulting in the fracture toughness increase.

\section{3-8 Oxidation Resistance}

Figure (8) shows the results of the heat treatment of $\mathrm{SiC}$ in air at $1300^{\circ} \mathrm{C}$ for different time intervals. Prolongation of the heat treatment from $2 \mathrm{~h}$ to $10 \mathrm{~h}$ gave rise for a slight weight gain increase from 1 to $1.6 \%$. SiC oxidation in air starts above $900^{\circ} \mathrm{C}^{(25)}$ to give glassy silica layer according to the following equation:

$$
\mathrm{SiC}+2 \mathrm{O}_{2} \longrightarrow \mathrm{SiO}_{2}+\mathrm{CO}_{2}
$$

The slight increase in the weight gain after heat treatment up to $10 \mathrm{~h}$ is due to the presence of $\mathrm{CO}_{2}$. The reaction between $\mathrm{SiO}_{2}$ and $\mathrm{SiC}$ causes the formation of volatile $\mathrm{SiO}$ and $\mathrm{CO}$. The above secondary solid state reaction depends upon the $\mathrm{O}_{2}$ activity in the interface and occurs at low $\mathrm{CO}_{2}$ pressure, i.e. at lower temperatures or short heat treatment intervals ${ }^{(26)}$. It seems that the rapid increase in the weight gain on increasing the heat treatment over $10 \mathrm{~h}$ is due to the easier transport of the volatile species.

Figure (9) shows the microstructure of $\mathrm{Si} / \mathrm{SiC}$ composite bodies heat treated at $1300^{\circ} \mathrm{C}$ for $2 \mathrm{~h}$. It shows a destroyed $\mathrm{SiC}$ fiber and $\mathrm{SiO}_{2}$ grains, which confirmed the occurrence of the secondary solid state reaction and the formation of the volatile $\mathrm{SiO}$ and $\mathrm{CO}$.

The kinetics of the oxidation reaction was studied using isothermal oxidation data. 
Because of the nature of the fibrous nature of the composite, the most likely controlling mechanism would be that of a diffusion controlled reaction. The relation between time of oxidation ( $\mathrm{t}$ ) and extent of reaction $(\mathrm{X})$ for cylindrical shapes (typical of fibers) takes the form ${ }^{(29)}$ :

$$
t=k \cdot(X+(1-X) \cdot \ln (1-X)
$$

The plot of the RHS of the above equation against time is shown in Figure (10). The linear character of the curve obtained (With a determination coefficient $R^{2}=0.995$ ) clearly supports the assumption that oxidation is controlled by diffusion of gaseous oxidation products through the silica layer.

\section{Conclusion:}

1- Laminated $\mathrm{Si} / \mathrm{SiC}$ composites derived from cellulosic fabrics were fabricated by process of lamination, carbonization, and infiltration with liquid silicon. The process is simple, low-cost and provides excellent shape-making capability.

2- The produced bodies exhibit a distinguished laminar structure with successive $\mathrm{Si}$ /SiC layers.

3- The biomorphous $\mathrm{Si} / \mathrm{SiC}$ composites retained the features of the original nativecellulose fabrics. The produced porous materials possess a novel, directed pore morphology which cannot be reached conventional ceramic processing technologies.

4- The Si content of the composites has a significant effect on the mechanical properties.

5- The Darcian permeability of the produced composites is $2.8^{*} 10^{-10} \mathrm{~m}^{2}$ which is the order of magnitude of gas filter supports and, therefore, may be suitable for several technological applications.

6- The oxidation reaction was found to be controlled by diffusion of gaseous products through the oxidation product layer.

\section{References:}

[1] P. C. Rojas, G. J. Piderit, andPToro, "Development of open-pore silicon carbide foams". Key Eng. Mater. 132 - 136 (1997) 1731- 4.

[2] P.Greil "Advanced engineering ceramics". Adv.Mater., 14 (2002) 709 -16.

[3] E. Passalacqua, S. Freni and F. Barone, "Alkali resistance of tap-cast SiC porous ceramic membranes". Mater. Lett. 34 (1998) 257 - 62.

[4] A. G. Evans and D.B.Marshall, "The mechanical behaviour of ceramic matrix composites". Acta metal. Mater., 37[10] (1989) 2567-83.

[5] M.j.o'Brien, F.M.capaldi and B.W.Sheldon, "A layered alumina composite tasted at high temperature in air" .J.Am .Cera.Soc., 83[12](2000)3033-40.

[6] K.S.Blanks, A.Kristofferson , E.Carlstrom and W.J. Clegg, " Gack deflection in ceramic laminates using porous interlayers" J. Eur. Ceram. Soc., 18 [13] (1998) $1945-51$

[7] W. J. Clegg, K. K. kendall, N. M. Alford, D. Birchall and T. W. Burton," A sample way to make tough ceramics". Nature (London), 347(1990), 455-57.

[8] F.R ebillat, J.lamon and R.Naslain "Properties of multilayered interphase in 
$\mathrm{SiC} / \mathrm{SiC} \quad$ chemical - vapor infiltrated composite with "weak" and "strong" interfaces". J. Am. Ceram. Soc., 81[9\}(1998)2315-26.

[9] D. H.Kuoand W. M. Kriven, "Fracture of multilayer oxide composite". Mater. Sci. Eng.,A241(1998)241-250.

[10] M.Omori and H.Takei, "pressureless sintering of SiC." J. Am. Ceram. Soc.,65 (1982)C-92.

[11] S.Ding, Y-P. Zeng, and D.Jiang ,"In-Situ reaction bonding of porous SiC ceramics".Mater.Charact.59(2008)140-143 .

[12] J. She, Z. Deng, J. D-Doni and T. Ohji." Oxidation bonding of porous silicon carbide ceramics". J. Mater. Sci, 37 (2002) 3615-22.

[13] K.G.Nickel, "The role of condensed silicon monoxide in the active - to passive oxidation transition of silicon carbide". J.Eu.Ceram.Soc., 9 (1992) 3-8.

[14] C.Badini, P.Fino, A.Ortona and C.Amelio, "High temperature oxidation of multilayered $\mathrm{SiC}$ processed by tape casting and sintering". J.Eu.Ceram.Soc., 22(2002) 2071-2079.

[15] H.E.Eaton and G.D.Linsey, "Accelerated oxidation of SiC CMC's by water vapor and protection via environmental barrier coating approach". J.Eu.Ceram.Soc., 22 (2002) 2741-2747.

[16] P. Griel, "Biomorphous ceramics from ligno-cellulosics", J. Eur. Ceram. Soc., 21(2001)105-118.

[17] C. Zollfrank and H. Sieber, "Microstructure evolution and reaction mechanism of biomorphous Si SiC ceramics" J. Am. Ceram. Soc., 88[1] (2005)51-58.

[18] H.J.Choi and J.G.Lee, "Continuous synthesis of silicon carbide whiskers". J.Mater.Sci., 30 (1995) 1982-1986.

[19] Y. Shin, C. Wang and G. J. Exarhos, "Synthesis of SiC ceramics by the carbothermal reduction of mineralized wood with silica", Adv. Mater.,17[1](2005)73-76.

[20] T. Hata, V. Castro, M. Fujiswa, Y. Imamura, S. Bonnamy, P. Bronsveld and H. Kikuchi,"Formation of silicon carbide nanorods from wood-+based carbons". Fullerenes Nanotubes Carbon Nanostruct, 13(2005)107-113.

[21] K. Vyshnyakava,G. Yushin, L. Peressllentseva and Y. Gogotsi,"Formation of porous SiC ceramics by pyrolysis of wood impregnated with silica".Int.J. Appl. Ceram. Technol.,3[6](2006)485-490

[22] Y. F. Lui, X. Q. Lui, H. Weiand G. Y. Meng, "Porous mullite ceramics from national clay produced by gel casting", Cerm. Int. 27(2001)1-7.

[23] S.Ding, S.Zhu, Y.Zeng and D.Jiang, "Fabrication of mullite-bonded porous silicon carbide ceramics by in situ reaction bonding" J.Eur.Ceram.Soc., 27 (2007) 20952102

[24] S.Ding, Y.Zeng and D.Jiang, "Gas permeability behavior of mullite - bonded porous silicon carbide ceramics". J.Mater.Sci., 42 (2007) 7171-7175.

[25] Q.Guo, J.Song, L.Liu and B.Zhang, "Relationship between oxidation resistance and structure of $\mathrm{B}_{4} \mathrm{C} / \mathrm{SiC} / \mathrm{C}$ composites with self - healing properties". Carbon, 37 (1999) 33-40.

[26] E.Fitzer and R.Ebi, "Kinetic studies on the oxidation of silicon carbide", Proceedings of the Third International Conference on Silicon Carbide held at Miami Beach, Florida, on 17-20 September 1973.

[27] R. N. Naslain, "SiC-materix composites: Nonbrittle ceramic for thermostructural application," Int. J. Appl. Ceram. Technol., 2 [2] 75-84 (2005).

[28] M. Presas, J.Y. Pastar, J.Segurado and C.Gonjàlez, "Strength and toughness of cellular SiC at elevated temperature," Eng. Fail. Anal., 16(2009)2598-2603.

[29] J. J. M. Orfao and F. G. Matins," Kinetic analysis of thermogravimetric data 
obtained under linear temperature programming", Thermo. Chim. Acta 390 (2002)195-211

Table (1) shows that the size and distribution of pores greatly effect by the infiltration of carbon by Si.

\begin{tabular}{|c|c|c|c|c|c|}
\hline Sample & $\begin{array}{c}\text { Median } \\
\text { pore } \\
\text { diameter, } \\
\mu \mathrm{m}\end{array}$ & $\begin{array}{c}\text { Average } \\
\text { pore } \\
\text { diameter, } \\
\mu \mathrm{m}\end{array}$ & $\begin{array}{c}\text { Total pore } \\
\text { area, m2/g }\end{array}$ & $\begin{array}{c}\text { Porosity, } \\
\%\end{array}$ & $\begin{array}{c}\text { Pore } \\
\text { diameter, } \\
\mu \mathrm{m}\end{array}$ \\
\hline $\begin{array}{c}\text { Carbon } \\
\text { Substrate }\end{array}$ & 65.63 & 0.162 & 57.91 & 79.55 & 0,0092 \\
\hline $\begin{array}{c}\text { Si/SiC } \\
\text { Composites }\end{array}$ & 16.75 & 0.106 & 17.19 & 59.23 & 0.0084 \\
\hline
\end{tabular}

Table (2) : The permeability and physico-mechanical properties of Si/SiC

\begin{tabular}{|c|c|c|c|c|c|}
\hline \multirow{2}{*}{$\begin{array}{c}\mathrm{Si} \\
\text { content,\% }\end{array}$} & \multicolumn{2}{|c|}{ Physical Properties } & \multirow{2}{*}{$\begin{array}{c}\text { Bending } \\
\text { Strength } \\
(\mathrm{MPa})\end{array}$} & \multirow{2}{*}{$\begin{array}{c}\text { Permeability, } \\
\text { K (D) (\%) }\end{array}$} & \multirow{2}{*}{$\begin{array}{c}\text { Fracture } \\
\text { Toughness } \\
\left(\text { MPa.m }^{1 / 2}\right)\end{array}$} \\
\hline & $\begin{array}{c}\text { Bulk Density } \\
\text { (\%) }\end{array}$ & $\begin{array}{c}\text { Apparent } \\
\text { Porosity (\%) }\end{array}$ & & & \\
\hline 4.5 & 0.7 & 48.13 & 34 & $9.72 \mathrm{E}+00$ & 2.66 \\
\hline 8 & 2.1 & 17.93 & 42 & ----- & ----- \\
\hline
\end{tabular}

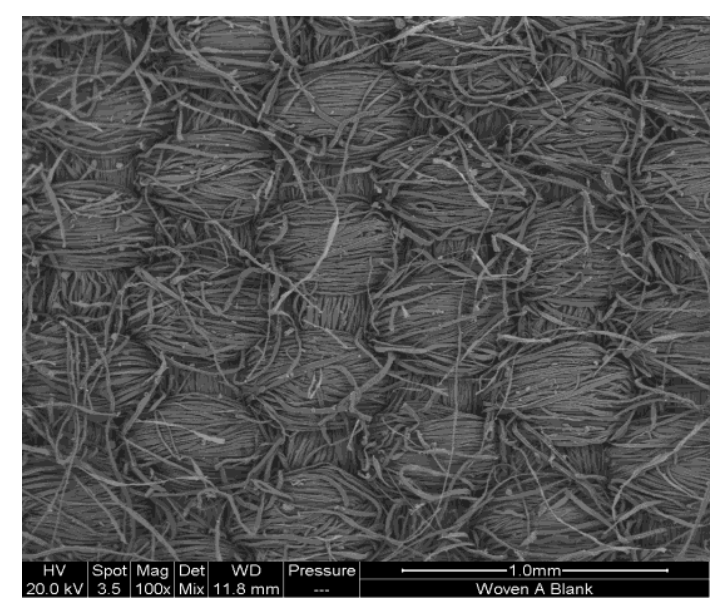


Fig. (1) Micrograph of textile fabric used to manufacture the ceramics.

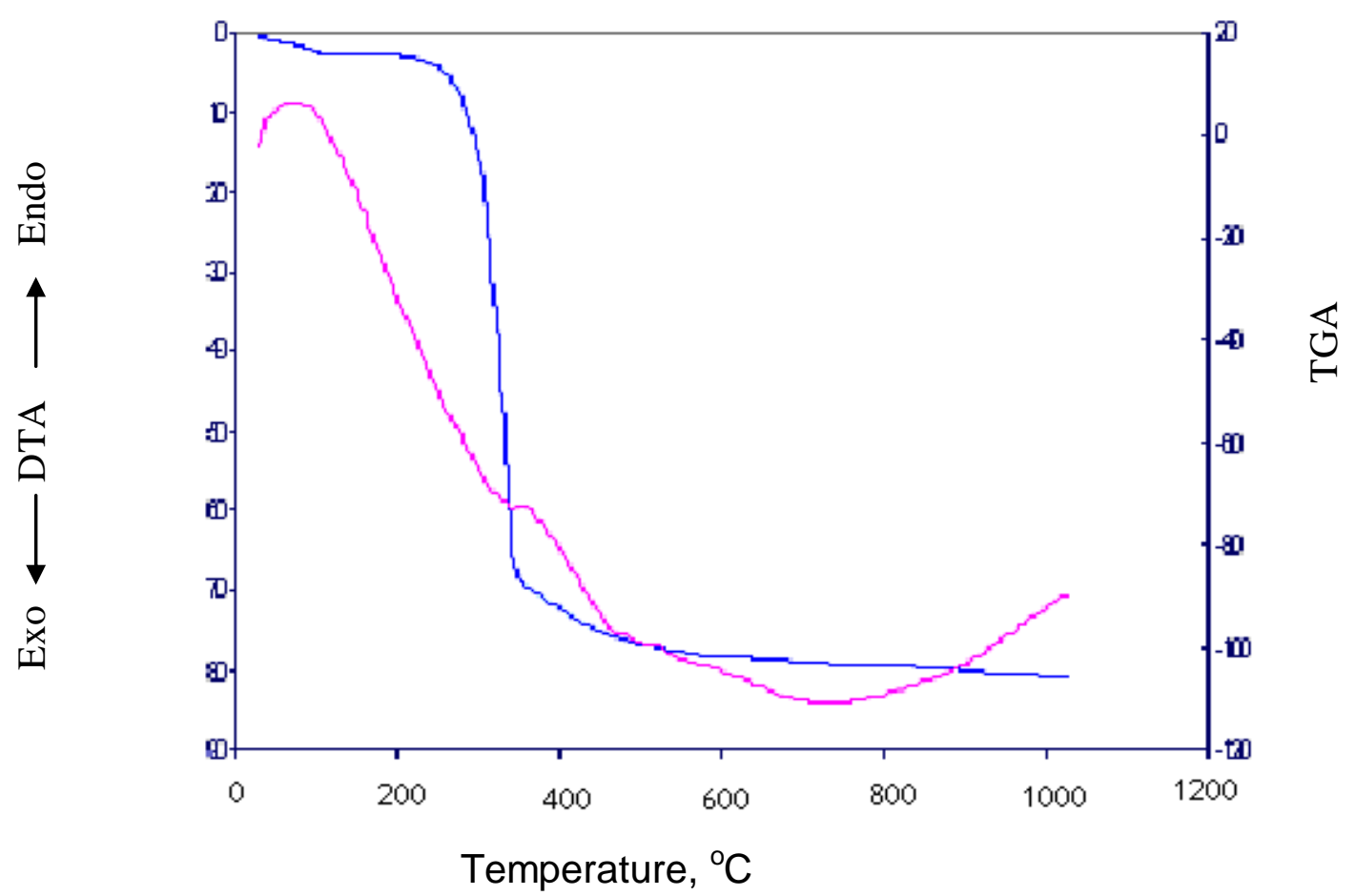

Figure (2) DTA and TG curves of the raw textile

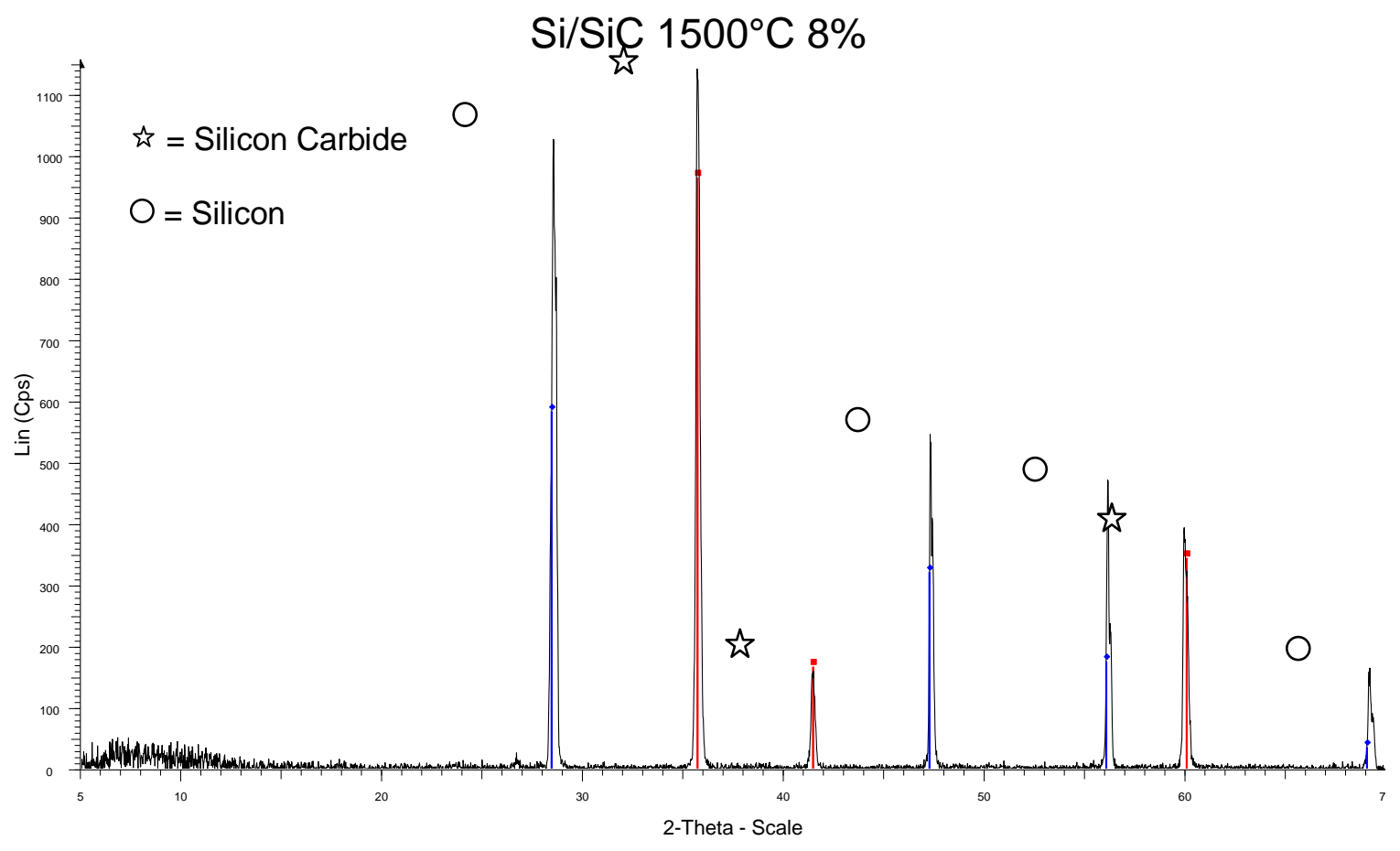

Fig. (3a) XRD patterns of the Si/SiC $8 \mathrm{Wt}$.\%. bodies fired at $1500^{\circ} \mathrm{C}$ 


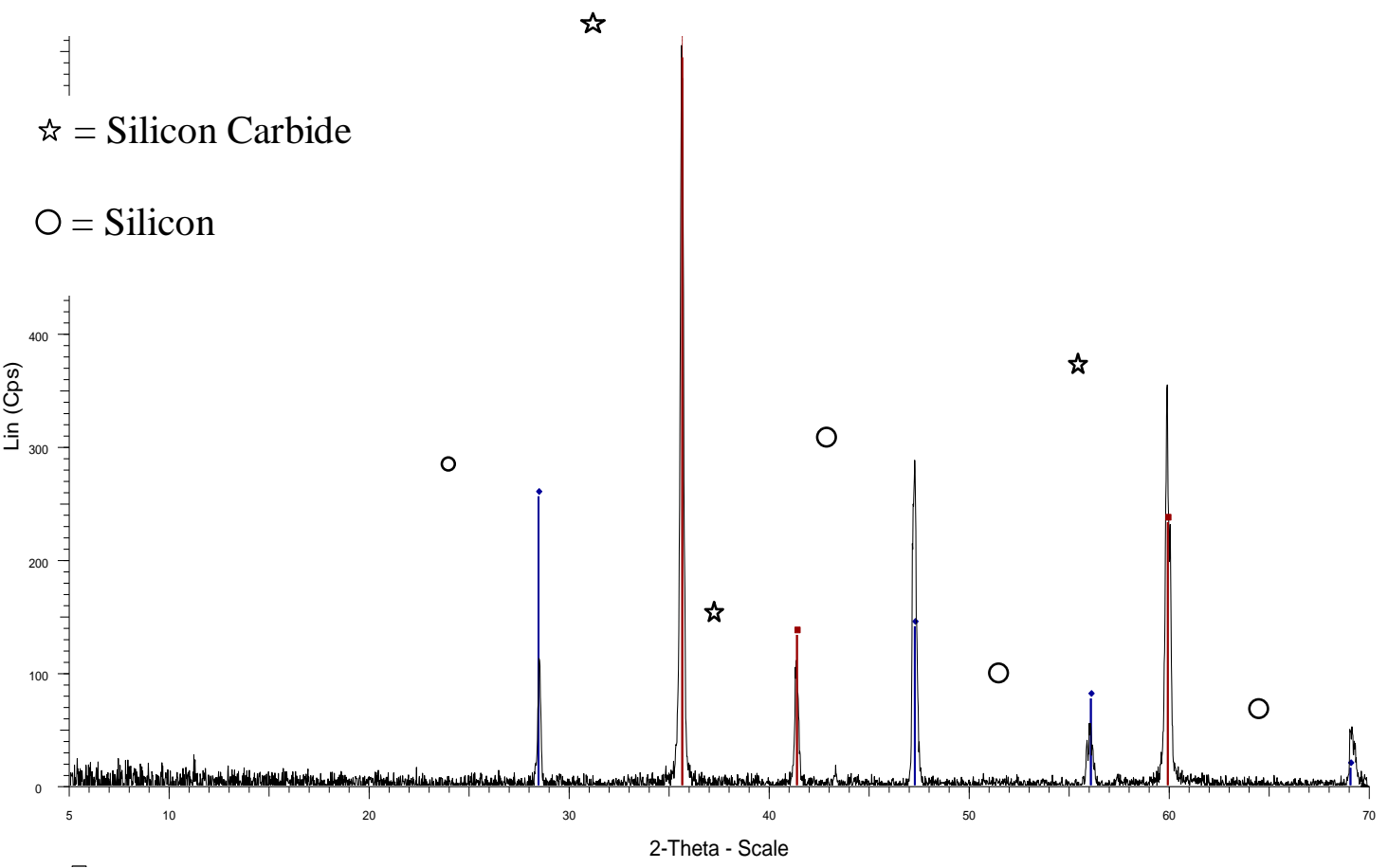

Fig. (3b) XRD patterns of the Si/SiC $8 \mathrm{Wt}$ \% bodies fired at $1500^{\circ} \mathrm{C}$
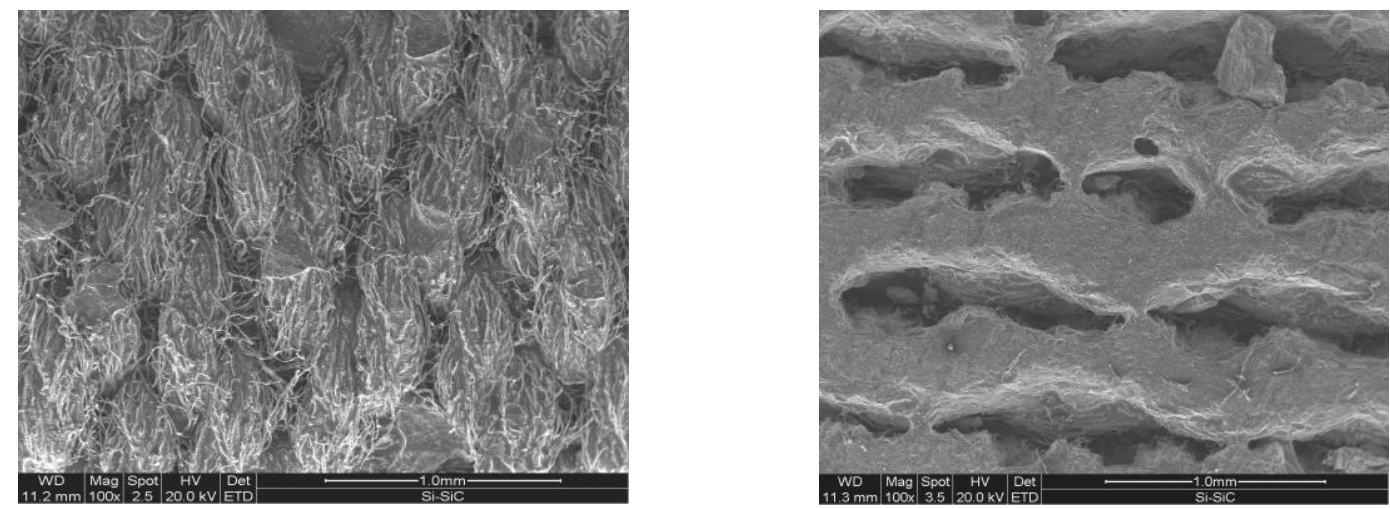

Fig. (4a) SEM micrograph of a single layer of laminated $\mathrm{Si} / \mathrm{SiC}$ composite fired at $1500^{\circ} \mathrm{C}$ showing retention of the native fabric architecture
Fig. (4b) cross section SEM micrograph of laminated $\mathrm{Si} / \mathrm{SiC}$ composite fired at $1500^{\circ} \mathrm{C}$ showing necks between the stacked layers. 


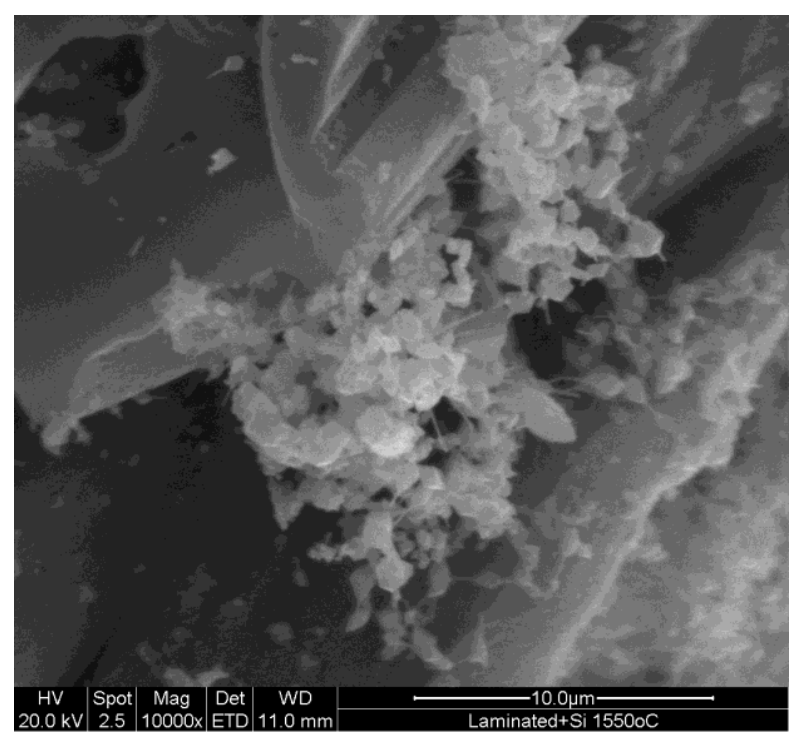

Fig. (4c): SEM micrograph of laminated Si/SiC

composite fired at $1500^{\circ} \mathrm{C}$ showing fine grains and whiskers of $\mathrm{SiC}$.

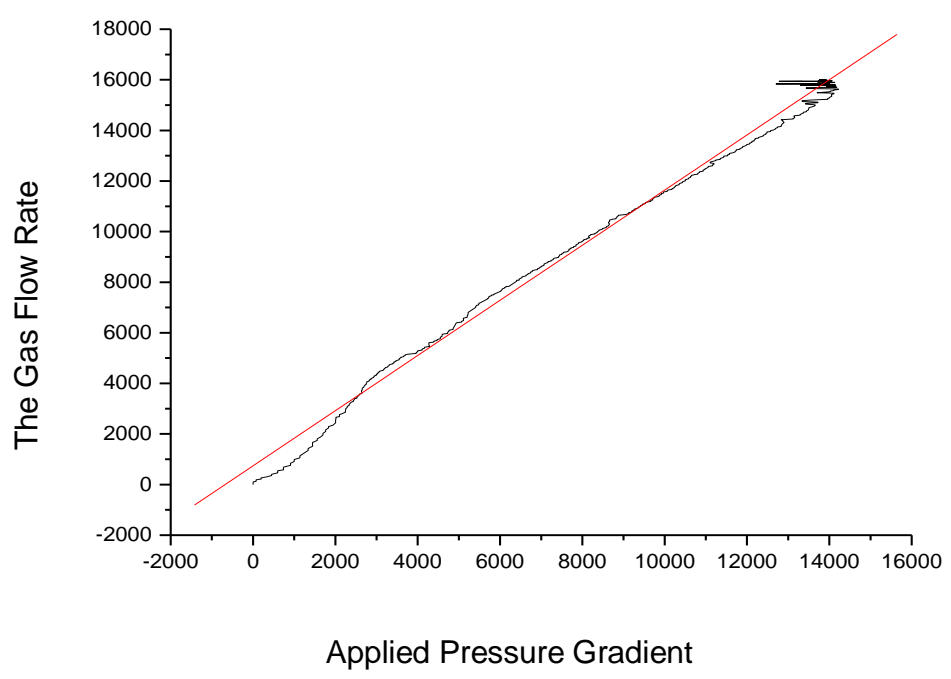

Fig. (5): The gas permeability of the $\mathrm{Si} / \mathrm{SiC}$ composites containing $4.5 \mathrm{wt} \% \mathrm{Si}$. 


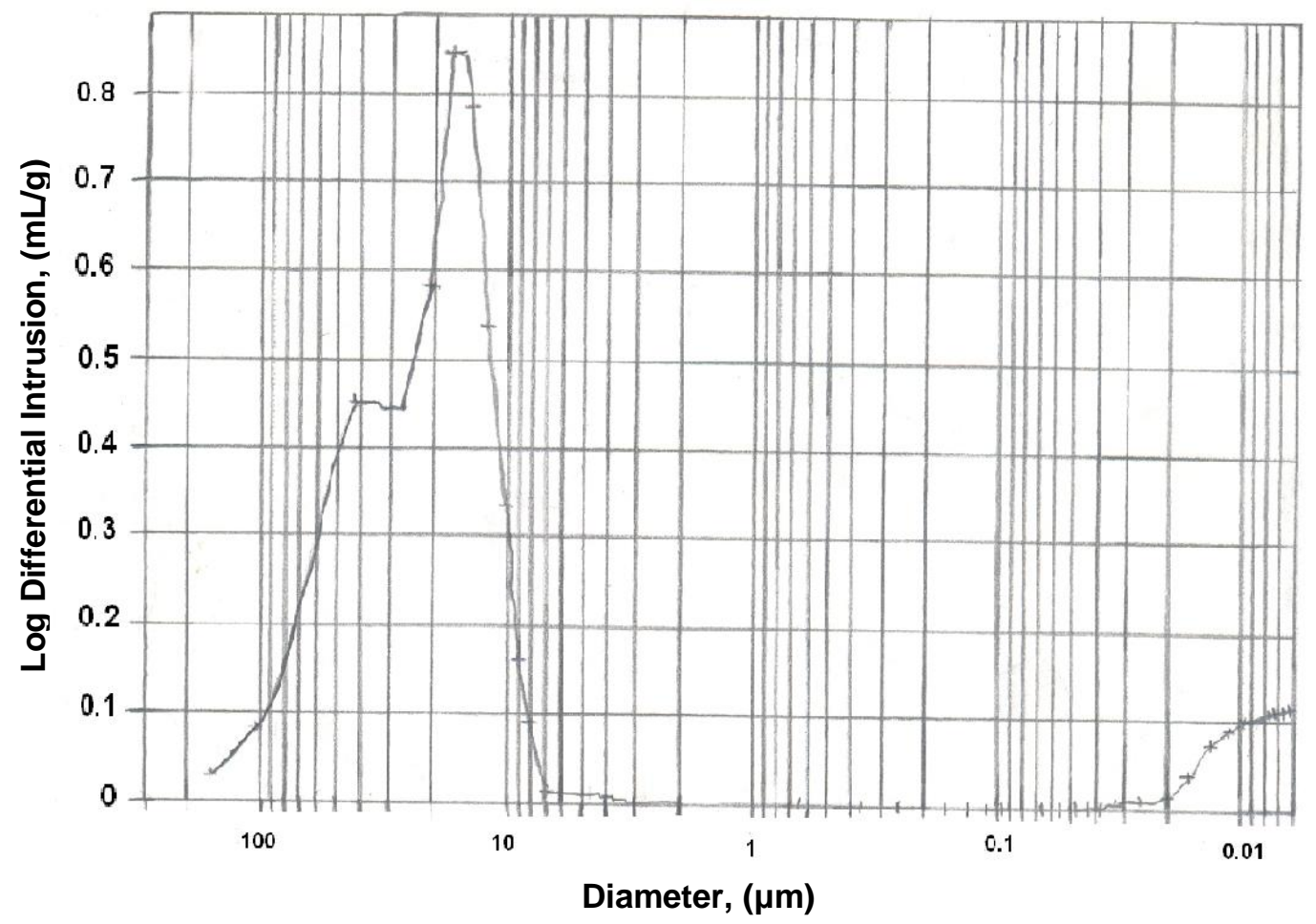

Fig.(6a) The analysis of pore size distribution carried out for the carbon substrate

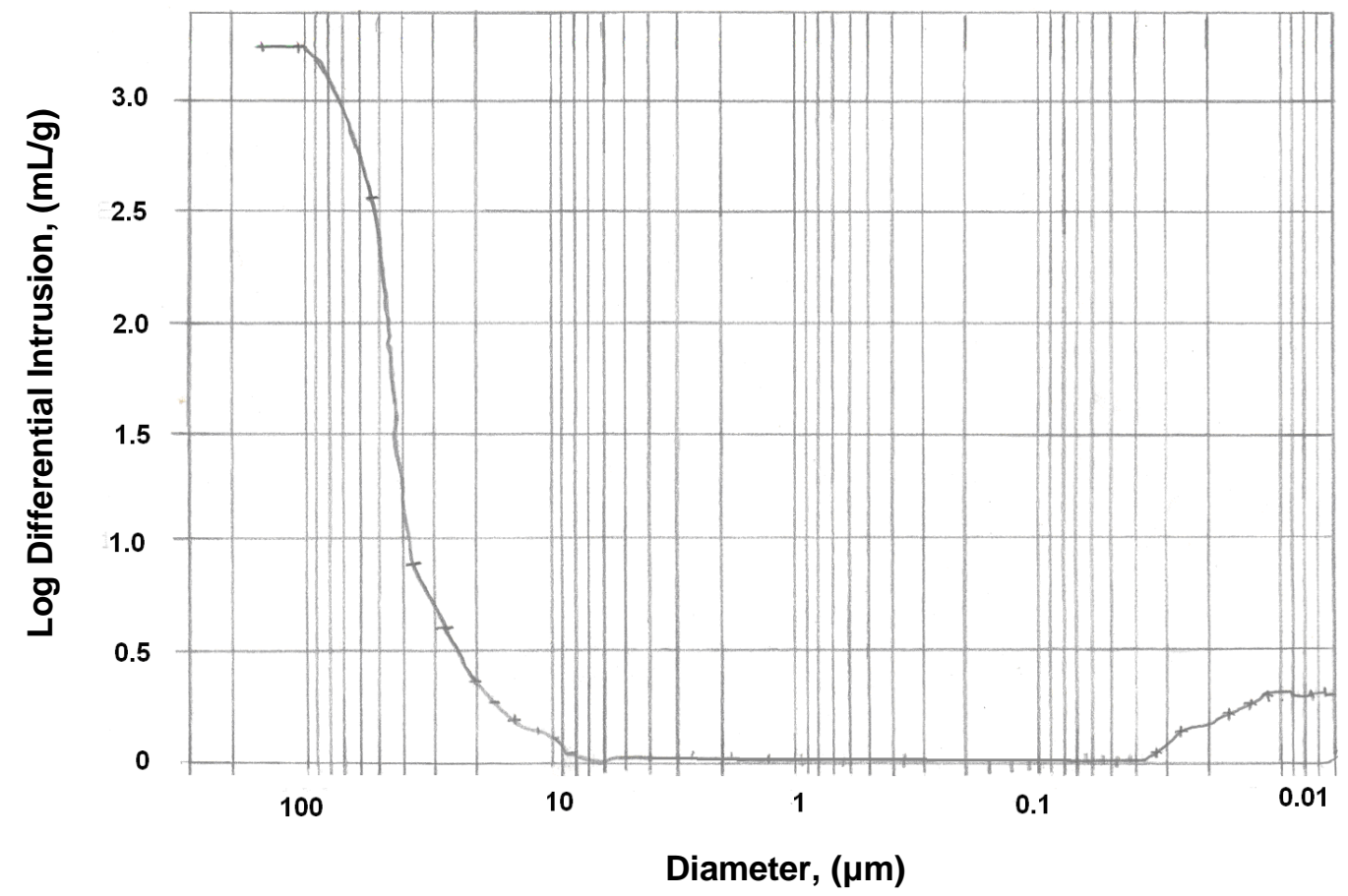

Fig.(6b) The analysis of pore size distribution carried out for the Si/SiC composite 


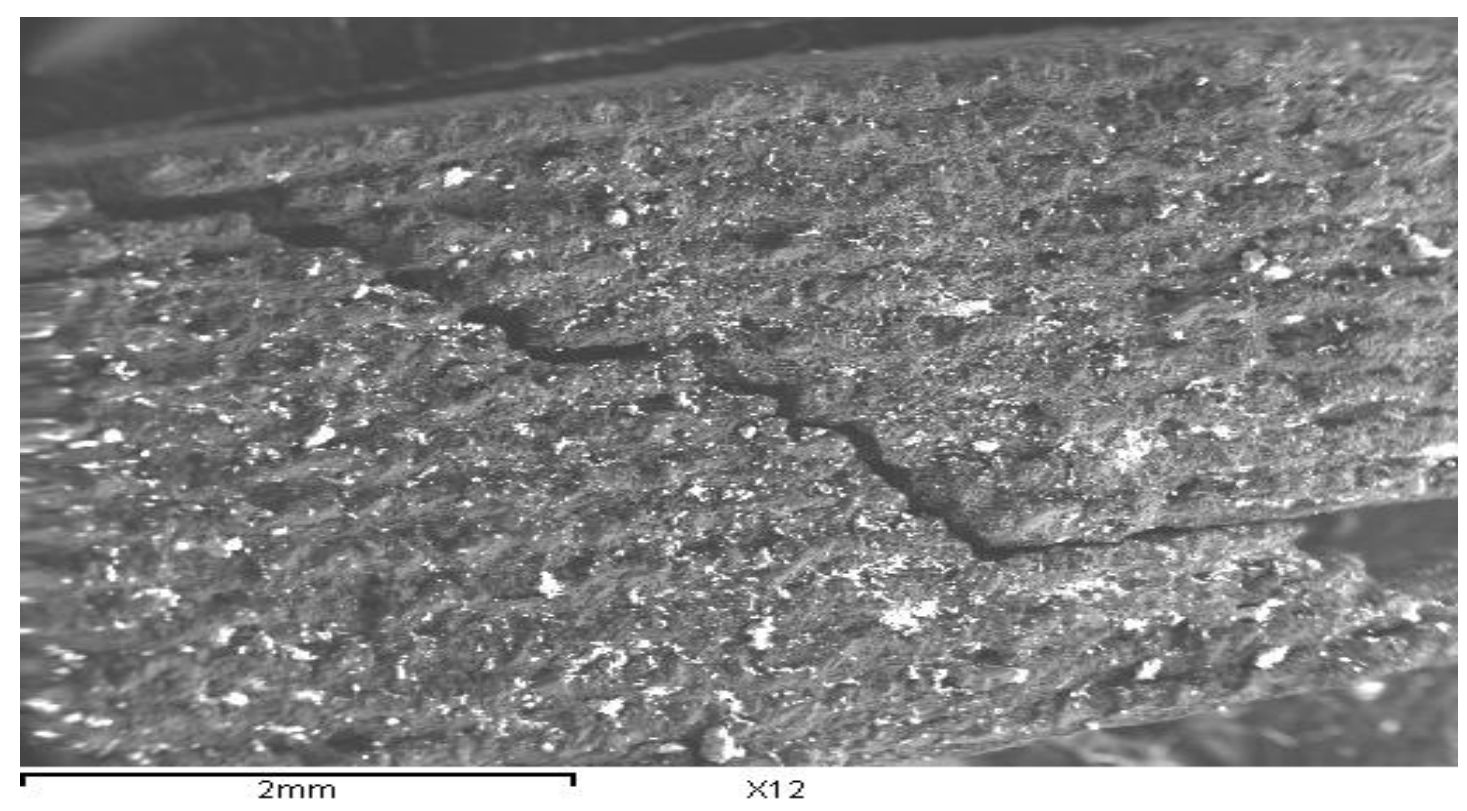

Fig. (7) Crack deflection occurs at the Si/SiC-Si/SiC interface.

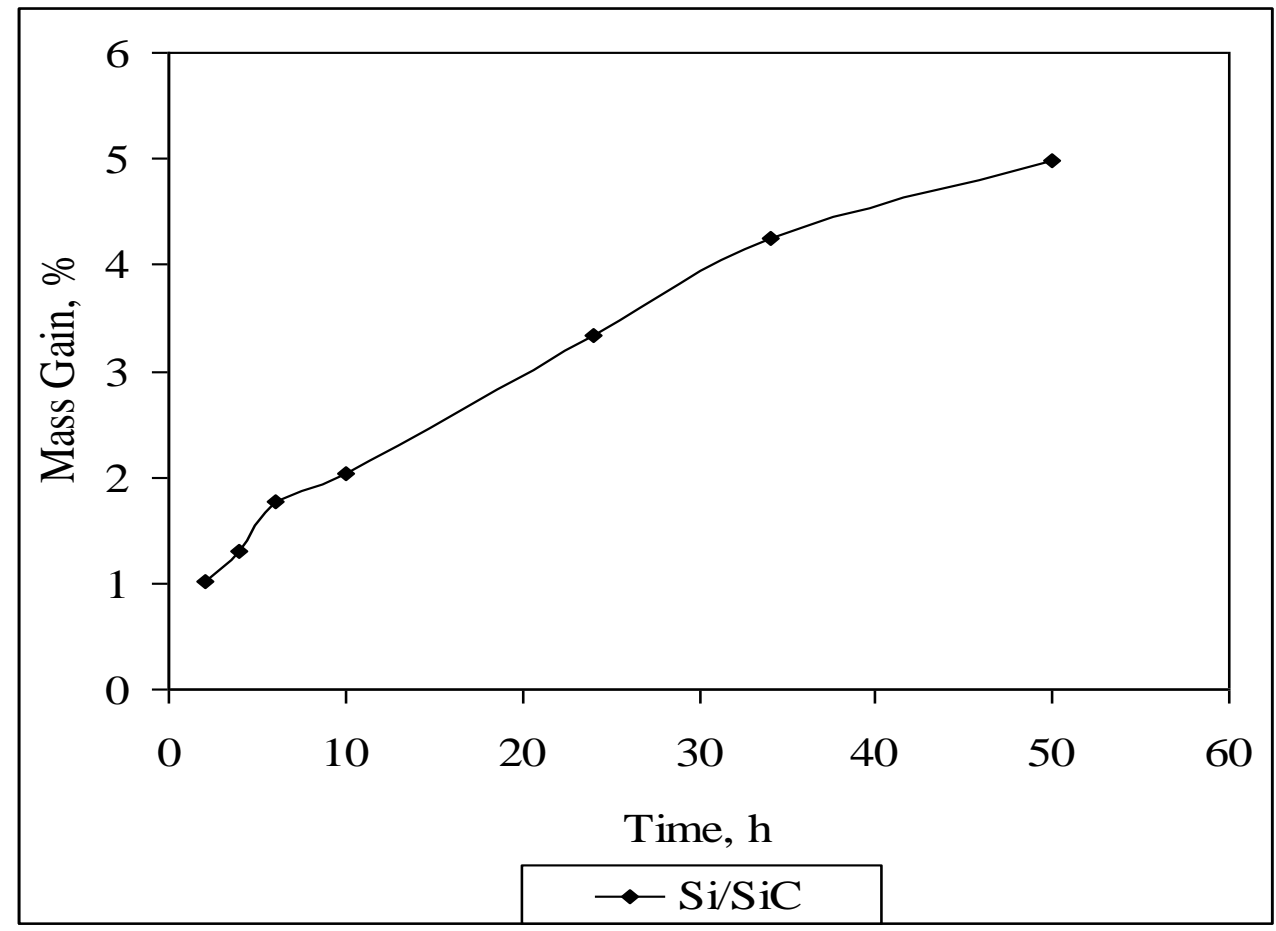

Fig.(8): Relation between weight gain and oxidation time 


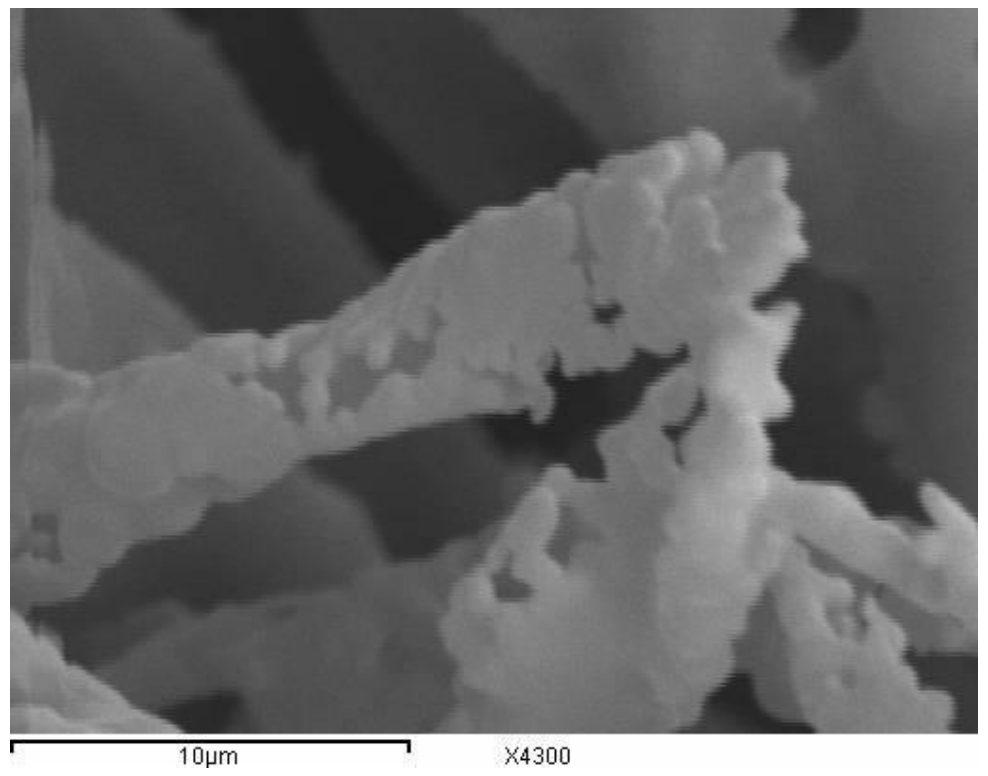

Fig (9): SEM micrograph of laminated $\mathrm{Si} / \mathrm{SiC}$ composite fired at $1500^{\circ} \mathrm{C}$ after oxidation in air at $1350^{\circ} \mathrm{C}$ for $2 \mathrm{~h}$.

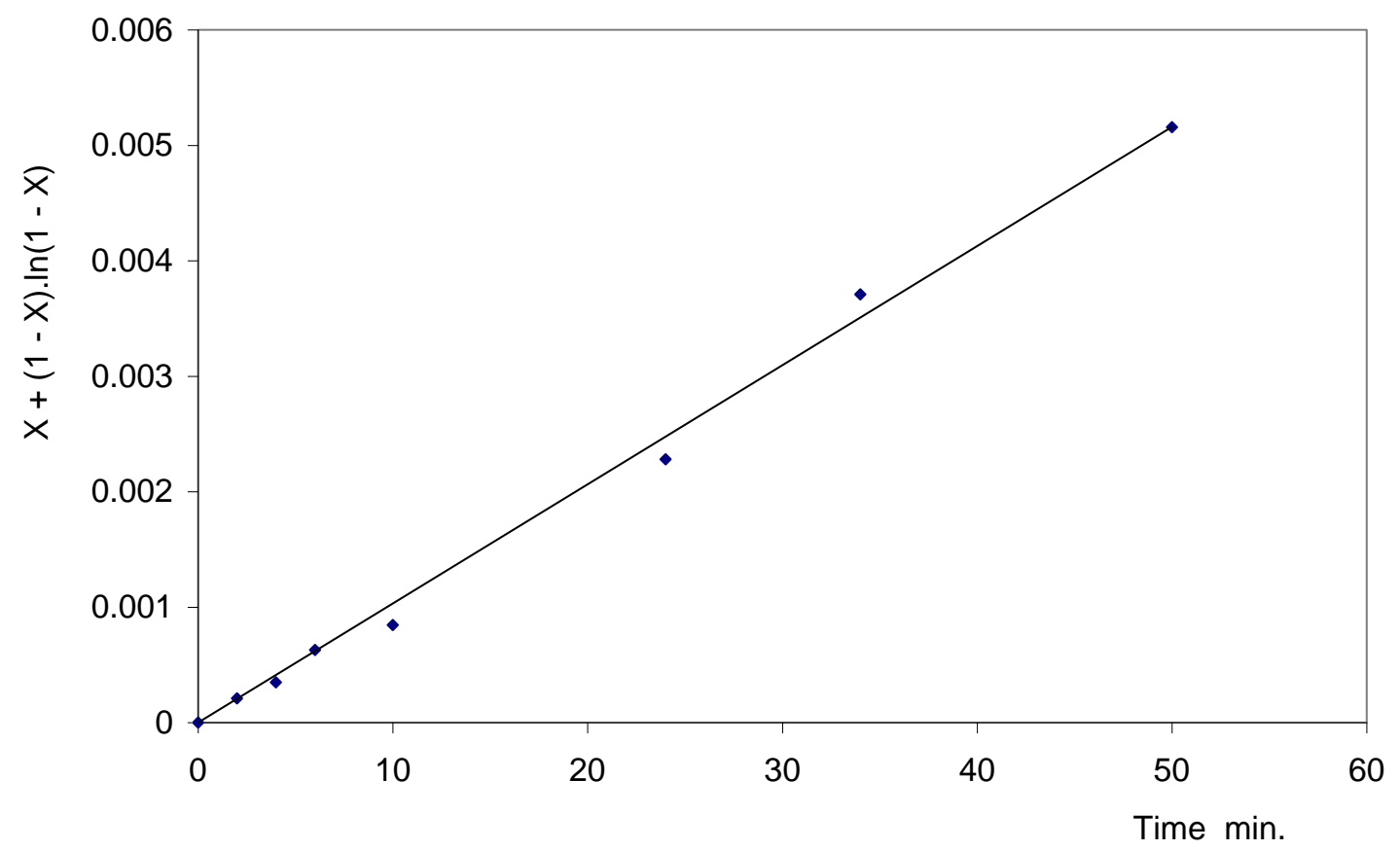

Fig (10): Plot of $f(X)$ against oxidation time for diffusion controlled reaction 